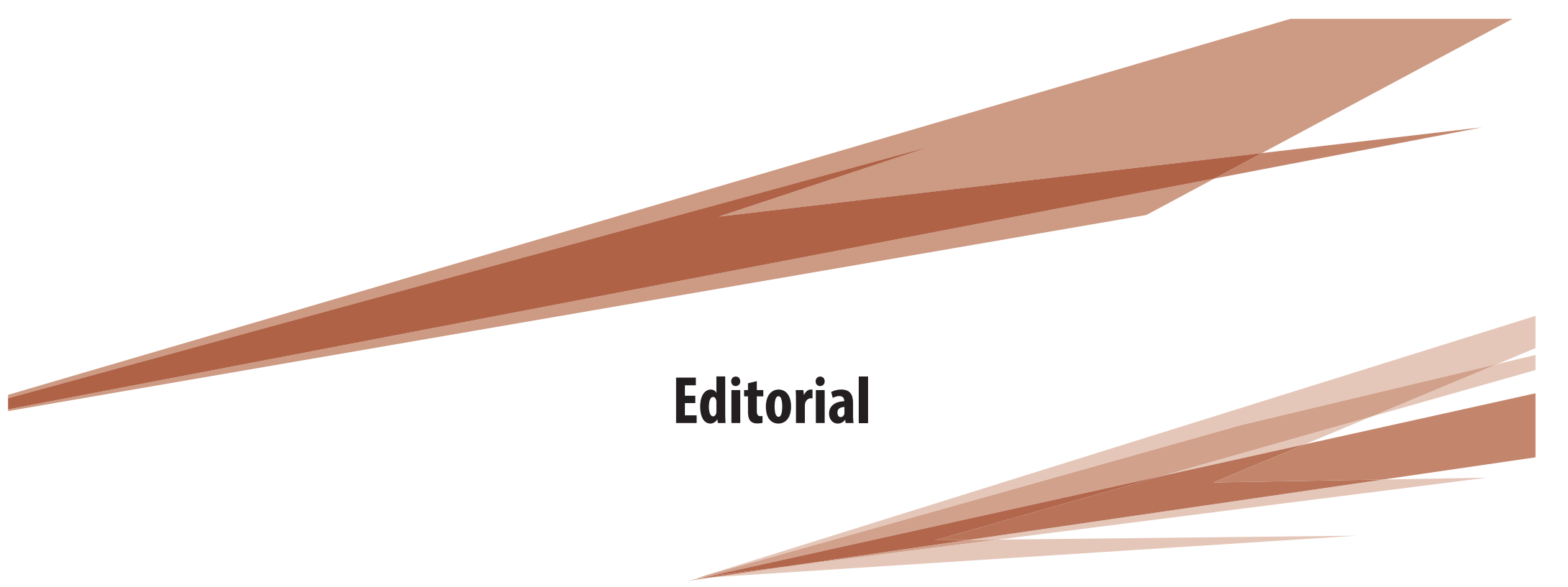

\title{
Ciudad y transporte
}

La convocatoria al dossier Ciudad y transporte: cambios y reflexiones históricas fue un éxito en cantidad y variedad. Se publican aquí finalmente siete artículos que tratan diversos aspectos, enfoques-categorías y espacios geográficos. Para describir y analizar lo que abarcan es útil una división gruesa del tema en dos grandes subtemas.

\section{Infraestructura y redes de transporte regionales y globales}

Los asentamientos urbanos prosperan o no según su forma de participación en nodos de redes regionales y globales de flujos de bienes, servicios y personas. El comercio de bienes para exportación, producidos en la ciudad, en la región o incluso fuera de estas cuando la ciudad no es más que sitio de intercambio, es el motor de sus dinámicas política, económica y demográfica. En cambio, las aglomeraciones urbanas aisladas suelen ser paupérrimas, y las excepciones confirman la regla. Bogotá es una de éstas: a pesar de ciertas leyendas en sentido contrario, Bogotá fue una ciudad paupérrima hasta que pudo conectarse al resto del país, especialmente mediante vía aérea (modalidad de transporte regional y global sobre la cual no recibimos artículos). La primera locomotora que llegó a Bogotá se subió por partes a lomo de mula. Las recuas de mulas fueron la modalidad de transporte de carga hasta los primeros años del siglo XX. Sólo bien entrado el siglo XX se pudo llegar por carruaje hasta Bogotá desde el río Magdalena, que era la comunicación con el mundo. Sin embargo, existió otra modalidad de servicio de transporte: los cargueros humanos, que impresionó a algunos de los cronistas extranjeros de finales del siglo XIX. El trazado era tan escarpado, que los viajeros encontraban más seguros los cargueros humanos. ${ }^{1}$ Una ciudad en esas condiciones no podía se más que paupérrima.

El dossier incluye variados casos de puertos marítimos. El asunto de los puertos es eminentemente público, en el siguiente sentido: casi que de manera natural el Estado interviene activamente, ${ }^{2}$ y esto incluye la infraestructura que soporta esos flujos, por diferentes razones: porque toca la seguridad del Estado, porque afecta playas y ríos que son clásicos bienes comunes,

1 Colombia: Comercio y transportes 1850-1929. Rafael Darío Muriel F., Editorial Pi, 2009.

2 Weber advirtió que el Estado históricamente ha intervenido en todo. Por consiguiente, aunque suene paradójico, hoy entendemos que una forma de intervención es dejar hacer, pero a esa no la considero como intervención activa.

tiempo\&economía

Vol. 5 N. 2 - Julio - Diciembre del 2018

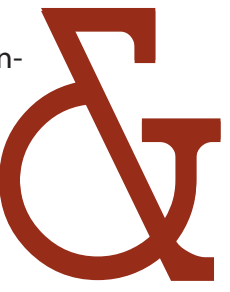


porque la infraestructura es costosa y el Estado puede ser el único actor que tenga el potencial financiero para acometerlas, porque encuentra fuentes de ingreso y lo más usual es que los aparatos de Estado sean fiscalistas y exploten las aduanas. Por otro lado, los niveles territoriales de gobierno local y nacional compiten por las atribuciones de gobernarlos, discutiendo si es el municipio, la provincia o 'la Nación' quien toma las decisiones públicas sobre el puerto. Además, esa infraestructura usualmente tiene una fuerte influencia sobre el ordenamiento de la ciudad: sus impactos positivos y negativos se manifiestan en competencia por el suelo, en propiedad, uso y rentas; los predios se valorizan y desvalorizan según la evolución de usos y dimensiones de la infraestructura.

Ramón, González y Gonçalvez relatan la evolución de Salvador de Bahía, hoy en día con tres millones de habitantes, cuarta ciudad en población de Brasil, fundada por los portugueses como capital y durante un tiempo prolongado puerto principal del comercio de azúcar y esclavos, y Las Palmas de Gran Canaria, ciudad puerto, co-capital con Santa Cruz de Tenerife de la Comunidad Autónoma de las Islas Canarias, España, hoy en día con 380.000 habitantes. Describen su desarrollo urbano en relación con sus puertos, a la vez que analizan semejanzas y diferencias.

En otro artículo del dossier, Mantuano hace lo mismo con el caso notable de Buenos Aires y sus puertos. Los dos artículos tienen enfoques bien diferentes. Desde los métodos de la geografía urbana, el primero mira la evolución a través de planos y mapas de la distribución urbana y regional y en su descripción, por decisión de enfoque y metodológica, los agentes no aparecen. Por ello la narrativa es impersonal: "El muelle... se construyó", "se inician las obras", "se trasladan los muelles". En cambio Mantuano pone su énfasis en los agentes: el empresario Eduardo Madero, el ingeniero Luis Huergo y otros, por un lado, y la financiación y las rentas por el otro. Tratándose de Buenos Aires, se describen en mayor detalle las decisiones del nivel nacional, y poco las del nivel local, si acaso tenía alguna jurisdicción en la época que abarca el estudio.

Silva, por su parte, describe la influencia del ferrocarril en el desarrollo de Varginha, una ciudad pequeña de 125 mil habitantes al día de hoy, que hace parte de una red regional de ciudades similares en el Estado de Mina Gerais en Brasil. Aquí el énfasis no es el impacto en el despliegue urbano sobre el territorio de la pequeña ciudad de la estación de ferrocarril, sino el desarrollo económico que genera la inserción de Varginha en la red de transporte por tren de una región cafetera al final del siglo XIX y comienzo del XX, durante el despegue capitalista del Brasil.

En un cuarto artículo de este subtema, Civitaresi plantea el problema del mantenimiento de los caminos rurales -vías terciarias- mediante la figura jurídica de Consorcio Caminero en la provincia de Córdoba, Argentina, a partir de los años cincuenta del siglo pasado, tras su establecimiento mediante estipulación legal nacional de 1952. Durante años, el 70\% del valor de las obras era financiado por el presupuesto nacional. El autor investiga cómo se sostuvo el esfuerzo cuando se suspendió esta fuente de recursos, empleando el concepto de capital social.

\section{Movilidad y accesibilidad-localización intra-urbanas}

Lo que hace especial al medio urbano es la riqueza que entrañan los intercambios internos, riqueza que supera con creces al conjunto de deseconomías de aglomeración. Por ello, 
una ciudad debe leerse como espacio público con islotes de uso y propiedad privados, y no como construcciones con espacios públicos anexos. La construcción de la ciudad se hace asociando cada inmueble con los demás, una característica de cada punto que denomino accesibilidad-localización. Cuando es prediseñada, bien sea por urbanizadores o por autoridades públicas, localización y accesibilidad están de manera principalísima en las ecuaciones: vías, andenes ${ }^{3}$ y senderos peatonales, además de ciclo-rutas y aquellas infraestructuras más pesadas, como BTR, metro, cable y tranvía, que pueden o no ir por las mismas vías en las que circulan otros medios de transporte.

Así, el segundo subtema en el que se divide el dossier es la manera como la sociedad encara la evolución de las necesidades de movilidad determinadas por la accesibilidad-localización intraurbanas en una ciudad que se transforma. El reto inherente para el que se emplea actualmente en Latinoamérica el término "movilidad" queda mejor descrito por la palabra "accesibilidad", pues ésta incluye también las decisiones individuales o colectivas, privadas o de autoridades públicas, que han dado lugar al ordenamiento territorial existente en cada momento, es decir, al despliegue territorial de los sitios y sus conectores. Los intercambios requieren movilización de personas y cosas, en mayor o menor medida según la distribución territorial y el sistema de movilidad sería entonces la combinación de infraestructura y tipo de vehículos, incluyendo los pies, que combinadamente determinan los tiempos y los costos de desplazamiento.

En muchas situaciones en las ciudades medianas y grandes, y en todo el casco urbano de cabeceras municipales pequeñas, la movilización se hace generalmente a pie, o con el apoyo de tecnologías rudimentarias que no convocan reglamentación. Uno puede imaginarse fácilmente cómo fueron apareciendo las zorras tiradas por seres humanos o por bestias, las carretillas, los carruajes para transporte individual y colectivo de tracción animal, los tranvías de mulas, como el que tuvimos en Bogotá hasta 1910, cuando comenzaron a cambiarse las mulas por electricidad.

Las variables de las que depende la aparición de artefactos de apoyo a la movilización más complejos y eficientes, como bicicletas, automóviles, trenes, camiones, tranvías, metros, motocicletas, y algunas modalidades de uso de estos vehículos como buses taxis y motataxis, son las mismas, aunque en estos casos necesitamos -más que imaginación-mirar la historia de las diferentes tecnologías y su inserción al consumo. Los aparatos y sus usos fueron inventados por personas para resolver su problema o para ofrecer a otros soluciones a sus necesidades de movilidad. Es la sociedad en marcha. Nada de esto esperó a que el Estado se pronunciase, o a que un miembro de algún congreso exigiera un invento. Los inventores van primero, la mayoría de las veces, si no siempre, bajo la expectativa de vender un producto. ${ }^{4}$

El transporte es una manifestación importante de la dinámica de la sociedad, porque desde hace siglo y medio es una gran industria, factor de productividad personal y social y, en el caso de los vehículos de uso personal, crea artículos de consumo durable, aquellos que generan clase media. El ex alcalde Jaime Lerner de Curitiba difunde en sus conferencias sus

3 Veredas, en varios países de Latinoamérica.

4 Escribo "la sociedad", aunque preferiría haber escrito "la sociedad civil". No lo hago porque por contingencias de la historia intelectual este término ha venido excluyendo las relaciones mercantiles entre las personas, recortando la potencialidad de estas palabras como herramienta de indagación. Las aglomeraciones humanas territorializadas (me refiero aquí a Estados) se distinguen por la manera como su cultura política hace el balance entre lo que es de la sociedad y lo que es del Estado. Eso que es de la sociedad debería llamarse sociedad civil, y por supuesto, tendría que incluir el mercado.

tiempo\&economía

Vol. 5 N. ${ }^{\circ} 2$ - Julio - Diciembre del 2018 
prevenciones sobre el automóvil, pero el dinamo económico de su ciudad son las gigantescas plantas de producción de esos satanases de cuatro ruedas. La dispersión urbana -urban sprawl- de norteamérica fue permitido y también desatado por la masificación del automóvil y la construcción de autopistas como opción para reconvertir la economía de guerra de Estados Unidos a una economía civil, manteniendo el pleno empleo después de la segunda guerra mundial. ${ }^{5}$

A medida que aparecen y cambian, las tecnologías para la movilidad exigen decisiones de ordenamiento urbano y pueden ser inconsistentes con las que se tomaron pensando en otras circunstancias. A mediados del siglo XIX, en Estados Unidos, el ancho de vía que separaba unidades de vivienda de a una (1) por manzana debía permitir el viraje en $U$ de un carruaje de un (1) caballo. ${ }^{6}$ Ese ancho de vía comenzó a tomarse como estándar, aunque ya no hubiera carruajes. No es cierto que nuestras grandes ciudades fueron diseñadas para el automóvil, pues en porcentajes importantes de su territorio no cabe un automóvil, y sus viviendas reducidas al mínimo no tienen espacio para guardar un vehículo tipo automóvil familiar. Esta insuficiencia urbana refuerza la segregación socioespacial, porque quienes mejoran su condición económica adquirirán automóvil, y se mudarán a lugares que dispongan de espacios adecuados para este.

Los colombianos hemos decidido -o los hechos nos han obligado a hacerlo así- que a medida que nuestras ciudades crecen y se complejizan no inventamos sino elegimos qué importar de un abanico de tecnologías diseñadas en otros ecosistemas tecno-económicos, para las soluciones individuales y para la oferta de servicio a uno o más usuarios simultáneos. La inventiva nacional es la reglamentación porque, si el Estado no está para prohibir, entonces, ¿para qué sirve? Los reglamentos resuelven algunas situaciones, pero como toda 'solución' en el caso de las políticas públicas, crean otros problemas. Para citar un ejemplo: el gobierno de Bogotá limitó en 1994 el número de taxis a los vigentes en ese momento, por solicitud del gremio, que ya tenía problemas de rentabilidad. Eso creó un mercado de cupos. Ahora el cupo cuesta cerca de dos veces el valor del aparato nuevo. Al aparecer UBER el cupo se desvaloriza, y los propietarios protestan, sin razón y con razón, que hay competencia desleal, entre otras razones, porque los UBER no pagan cupo.

Otro de muchos ejemplos: hace años se importaban algunas motos para un mercado reducido. De pronto, en los últimos años, los pobres urbanos comenzaron a comprarlas y a usarlas masivamente, experimentando en carne propia las virtudes de una solución individual motorizada, más flexible y eficiente incluso que el automóvil. Es tan flexible que en la noche se puede guardar en la sala de la casa. Ahora entienden más eso del mundo libre, el eufemismo de la guerra fría: con su motocicleta los pobres han logrado vencer la esclavitud de las distancias, para ir a donde quieran a la hora que quieran, y posiblemente además han dejado de sufrir el deficiente transporte público colectivo (TPC) como un castigo a su pobreza. Nunca les importó, ahora menos, el discurso político que los consideraba postmodernos porque no tenían dinero para adquirir un automóvil. Una de las consecuencias más interesantes de la proliferación de este vehículo es que ahora el TPC tiene que competir con la motocicleta como mé-

5 Piense el lector en un experimento mental: suponga que una mañana, los ciudadanos le hicieran caso al alcalde que considera que el automóvil es el enemigo público número uno, y decidieran guardarlo para siempre. ¿Qué pasaría? 
todo para movilizar 'clases trabajadoras'. En la costa atlántica colombiana, además, apareció el mototaxismo. La motocicleta misma ya producía una crisis, pero se agravó al máximo en algunas ciudades porque el mototaxismo hizo inviable el TPC. Motiva a los taxistas a quemar sedes de las alcaldías que lo autorizan, una faceta de nuestra versión de la destrucción creativa de Schumpeter.

La competencia entre motocicletas y TPC es 'desleal', pues la primera tiene como fuente decisiones individuales, fáciles de tomar, con amplias ofertas de crédito cuyas cuotas en buena parte se pagan con ahorros en pasajes diarios, que cubren buena parte de los costos de adquisición y operación. En cambio, el TPC requiere decisiones del sistema político en el cual el recelo, con todo lo que engloba, se envuelve en un equívoco ideológico-conceptual: una visión recortada de lo público. Algunas vertientes políticas que debaten sobre decisiones en la accesibilidad o movilidad dejan ver una con-fusión entre 'lo público' y el 'funcionariado público'. El transporte, según su punto de vista, es un tema público porque especialmente es un servicio que debe ser prestado por el Estado, con funcionarios de su nómina. ${ }^{7}$ La iniciativa empresarial privada se destaca (¿quizás se censura, sin explicitarlo?) porque está animada no por el ánimo de servicio al público, sino por la ganancia del empresario. Los funcionarios de la nómina estatal, en cambio, 'no ganan', pues serían androides unidimensionales cuya lógica de acción es el servicio desinteresado a los demás. El Estado pareciera que se define como 'lo perfecto', la síntesis por definición del bien común, no como una asociación en la que compiten intereses en la toma de decisiones que obligan a todos, bajo la amenaza, en última instancia, del uso de la fuerza. Cuando domina la primera visión, la intervención del Estado en cualquier cosa es válida en sí misma, no hay que justificarla en cada caso. Basta equiparar lo público con lo colectivo, darle una connotación de solidario, y contrastarla con lo individual que, como es egoísta, ya de por sí es moralmente censurable.

Superando este equívoco y sus ramificaciones, los dilemas colectivos de la accesibilidad-localización y las concomitantes necesidades de movilidad intraurbana, deben mirarse desde la evolución de necesidades y expectativas de las personas, por una parte, y con el telón del fondo del ecosistema tecno-económico, por la otra, ambos en cambio permanente. Complementa el escenario el sistema político que puja porque el aparato estatal intervenga en todo, en tal o cual dirección, o por la no intervención. Para las necesidades de las personas aparecen alternativas de solución de diferente tipo, individual y colectivo. Y todas resultan ser de interés público. Las individuales porque necesitan de infraestructura, de regulación (como mínimo-evidente, las normas de tránsito) y además, porque la suma de muchas decisiones individuales correctas puede producir tragedias colectivas. Esto se aplica también al TPC: Transmilenio, el BTR de Bogotá, es víctima de su éxito: los usuarios se volcaron a su uso; el patrón de ocupación urbana se acomodó a la oferta de transporte, lo que contribuyó a saturar el sistema a una velocidad por encima de la capacidad del sistema político para ampliarlo. ${ }^{8}$

La perentoriedad de regulación estatal sobre la oferta brindada por unas personas a los demás es menos evidente. Casi siempre ha sido la solicitud a las autoridades públicas para crear

7 Eso explica por qué estos proyectos políticos tienen una aceptación notable del sindicalismo público.

8 En Bogotá un alcalde autodeclarado de izquierda calificó el sistema de buses como algo de derecha y los rieles como de izquierda. Una innovación, pues en general los partidos clasificados de derecha son los que promueven las grandes infraestructuras.

tiempo\&economía

Vol. 5 N. 2 - Julio - Diciembre del 2018 
un monopolio explotado por los primeros que llegaron a ofrecer el servicio. Los dilemas verticales asociados a la oferta del servicio de transporte público colectivo y de servicio de transporte público masivo son muy interesantes, cuando trascienden la crítica, velada o no, de que hay unos particulares lucrándose por prestar el servicio o por ofrecer las máquinas.

El imperativo de encontrar 'la solución al problema de la movilidad' es equivocado, porque supone la condición perfecta a alcanzar, que no existe. Recuerda el aplazamiento de la compra de nuestro primer computador personal a la espera del próximo modelo, que será el definitivo. ${ }^{9}$ Las personas buscan satisfacer sus necesidades de movilización, y aparecen ofertas para atenderlas, mediante la movilidad o la re-localización. La precariedad económica de la sociedad (sector privado y sector público) fue la causa de base para el notable lapso entre los planes de infraestructura y su puesta en marcha a comienzos de siglo, como se puede leer en los artículos sobre los puertos y el ferrocarril para el transporte extraurbano o del tranvía de Bogotá para el caso de la movilidad intraurbana, y se suma a las características descritas de la toma de decisiones públicas. El capital social de una sociedad, la capacidad de actuar colectivamente, se debería describir como la capacidad de resolver las incongruencias que resultan de las decisiones individuales, o sea, de la libertad. El Estado es una manifestación, notable eso sí, de la manera como el sistema político lee los conflictos, y de esa lectura depende la capacidad de resolver los dilemas de acción colectiva.

Sugiero al lector tener estas consideraciones como telón de fondo del tratamiento de las situaciones analizadas de los artículos de detalle dentro de este segundo subtema, denominado "Movilidad y accesibilidad-localización intraurbana". Ellas también permitirán poner de presente asuntos que no alcanzaron a ser cubiertos en un tema tan vasto, interesante e importante.

El artículo de Scabelo, da Silva y Balassiano, interrelaciona localización y sistema de transporte para calcular un índice global para la ciudad de Petrópolis (300,000 habitantes, a 70 km de Río de Janeiro, "la primera ciudad planeada de Brasil") a partir de indicadores de accesibilidad, desde la perspectiva de desarrollo humano del PNUD. Los autores definen sistema de transporte con una mirada de distribución espacial, sin incluir los costos a los usuarios de diferentes modalidades, especialmente sin incluir la proporción de sus ingresos que se destina a sólo movilizarse. Se destaca el propósito de los autores de incluir la accesibilidad urbana en los indicadores de equidad, pero ellos reconocen que aún se está en el proceso de precisión de los indicadores. En el caso de Bogotá -pongo el ejemplo para ver la potencialidad de la idea de incluir los costos del desplazamiento en el análisis de las desigualdades urbanas de accesibilidad- los sectores de altos ingresos y una porción importante de familias de ingresos medios tienen costos mucho más altos de desplazamiento que las familias de ingresos bajos, aunque en general la porción de sus ingresos empleada en el acto simple de movilizarse (que idealmente debía ser tiempo igual a cero y costo igual a cero) de los sectores de ingresos bajos es bastante más alta que en el caso de los ingresos altos. En Bogotá son notables el inmenso costo y tiempo en los que incurren las familias de ingresos elevados en el transporte escolar de los hijos, pues el ordenamiento territorial espontáneo envió los colegios privados en los que estudian los hijos de las clases altas a las afueras de la ciudad. En contraste, los colegios

9 Tampoco parece adecuada la idea según la cual hacer más vías no sirve pues ante la oferta, se volverán a congestionar. Se parece a la objeción a poner bibliotecas: si se abre una biblioteca, la gente leerá los libros y va a pedir más libros. 
públicos, que por focalización atienden familias de bajos ingresos, se localizan en las periferias, cercanos a las viviendas de los escolares. Cabe preguntarse si se debe incluir un factor de calidad en los indicadores de accesibilidad, pues la segregación socioespacial también debería considerar la calidad de la educación y de salud a las que se tiene acceso para reducir los costos de movilidad.

Los otros artículos en este subtema trabajan dos tipos de oferta del servicio de movilidad en sendas ciudades colombianas. Cifuentes se pregunta por la influencia que tuvo la extensión del tranvía al suroriente del casco urbano básico de Bogotá, entre 1900 y 1940. Promotores urbanos privados impulsaron diferentes propuestas de urbanización y procuraron la extensión del tranvía para promover las ventas, presionando a las autoridades públicas o procurando que actores privados se animaran a prestar el servicio de transporte público. La zona terminó consolidándose para vivienda obrera. ${ }^{10}$ Como era de esperar -y así lo corrobora el autor- con tranvía o sin tranvía, familias pobres terminaron instalándose en la zona. Resolvieron la accesibilidad al empleo como pudieron, mediante ofertas que llaman informales o con viajes a pie que el autor no describe.

Vinasco formula la misma pregunta para Cali, pero referida a la relación entre la urbanización informal de quienes eligen la localización de vivienda en "donde les toca elegir", y la provisión del servicio de transporte mediante buses. Su conclusión en últimas es similar a la de Cifuentes: los pobres se hacen donde pueden, y los que viven de ofrecer el servicio de movilidad llegan donde están los clientes con soluciones de calidad y costo coincidentes con la necesidad y disposición de ellos.

Paul Bromberg

Ex Alcalde de Bogotá (1997)

Fundador del Instituto de Estudios Urbanos de la Universidad Nacional de Colombia Investigador y consultor en gobierno urbano metafora_99@yahoo.com

https://doi.org/10.21789/24222704.1363

10 Un eufemismo de la época para referirse a'pobre', que se confundía también con las clases trabajadoras, éste muy revelador porque en el afán de ser elegantes supone que lo que hace un gerente no clasifica como trabajo.

tiempo\&economía

Vol. 5 N. 2 - Julio - Diciembre del 2018 